\title{
APROXIMAÇÕES ENTRE E. HUSSERL E C. G. JUNG: DA CRÍTICA À FUNDAÇÃO DE UMA NOVA PSICOLOGIA
}

Carolina Rodrigues de Oliveira

Universidade Federal de Uberlândia

Tommy Akira Goto

Universidade Federal de Uberlândia
Recebido em: 20/04/2020

$1^{\text {a }}$ revisão em: 18/09/2020

Aceito em: 02/11/2020

\section{RESUMO}

Pode-se encontrar aproximações entre a proposta fenomenológica de Edmund Husserl (1859-1938) com algumas ideias da Psicologia Analítica de C. G Jung (1875-1961), principalmente no que se refere à crítica que ambos promoveram em relação à Psicologia científica e à concepção de uma Psicologia mais humana. Esse estudo, seguindo o procedimento da pesquisa qualitativa teóricobibliográfica, teve o objetivo de explicitar e, em seguida, aproximar as duas propostas epistemológicas e metodológicas, trazendo os conceitos e estruturações da Fenomenologia e da Psicologia Analítica, correlacionando os pontos de convergência nos quais se equiparam e/ou complementam. Como resultado, observou-se que, tanto Husserl quanto Jung, elaboraram outra concepção filosófica, reagindo ao materialismo e naturalismo positivista; ampliaram o conceito de experiência (empiria); desenvolveram um método de investigação que considera a subjetividade pura; e, por fim, fundaram uma nova Psicologia.

Palavras-chave: fenomenologia; psicologia analítica; experiência; método fenomenológico; inconsciente. 


\section{E. HUSSERL AND C. G. JUNG: FROM CRITIQUE TO FOUNDING A NEW PSYCHOLOGY}

\section{ABSTRACT}

It is possible to find approximations between Edmund Husserl's phenomenological proposal (1859-1938) and some ideas from C. G Jung's Analytical Psychology (1875-1961), mainly regarding the criticism that both promoted in relation to scientific Psychology and the conception of a human Psychology. This study, following the procedure of theoretical-bibliographical qualitative research, had the objective of explaining and bringing together the two epistemological and methodological proposals, bringing the concepts and structuring of Phenomenology and Analytical Psychology, correlating the points of convergence in which they are equated and/or complementary. As a result, it was observed that Husserl and Jung elaborated another philosophical conception, reacting to positivist's materialism and naturalism; expanded the concept of experience (empiria); developed a method of investigation that considers pure subjectivity; and, finally, founded a new Psychology.

Keywords: phenomenology; analytical psychology; experience; phenomenological method; unconscious.

\section{E. HUSSERL Y C. G. JUNG: DE LA CRÍTICA A LA FUNDACIÓN DE UNA NUEVA PSICOLOGÍA}

\section{RESUMEN}

Se pueden encontrar aproximaciones entre la propuesta fenomenológica de Edmund Husserl (1859-1938) con algunas ideas de la Psicología Analítica de C. G Jung (1875-1961), sobre todo en lo que se refiere a la crítica que ambas promovieron en relación con la Psicología científica y la concepción de una Psicología más humana. Este estudio, siguiendo el procedimiento de la investigación cualitativa teórico-bibliográfica, tuvo como objetivo explicar y luego reunir las dos propuestas epistemológicas y metodológicas, trayendo los conceptos y la estructuración de la Fenomenología y la Psicología Analítica, correlacionando los puntos de convergencia en los que se equiparan y/o complementan. Como resultado, se observó que Husserl y Jung elaboraron otra concepción filosófica, reaccionando al materialismo y al naturalismo positivista; ampliaron el concepto de experiencia (empiria); desarrollaron un método de investigación que considera la subjetividad pura; $y$, finalmente, fundaron una nueva Psicología.

Palabras clave: fenomenología; psicología analítica; experiencia; método fenomenológico; inconsciente. 


\section{INTRODUÇÃO}

A racionalidade cartesiana norteou a ciência comumente chamada de moderna a partir do século XVIII, período em que René Descartes (1596-1650), Isaac Newton (1643-1727) e outros filósofos contribuíram para a "matematização da representação do mundo" (Henry, 1998, p. 20). As "filosofias naturais" foram se tornando ciências, passando a ser "exatas" e ideais para o desenvolvimento tecnológico, bem como critério para explicar o funcionamento do mundo, sendo o primeiro estímulo para uma revolução científica (Henry, 1998).

O subsequente desenvolvimento do método experimental nas décadas seguintes, com a tendência empírico-naturalística, acabou orientando o conhecimento em quase todas as áreas e se sobrepôs aos saberes filosóficos (Henry, 1998), o que aconteceu com a Psicologia, por exemplo. Isso condicionou, durante um longo período, o caráter quantitativo e materialista das pesquisas, de forma a determinar padrões físicos, sociais e, até mesmo, individuais.

$\mathrm{Na}$ segunda metade do século XIX, os ideais científicos positivistas foram consolidados, rompendo definitivamente com a Filosofia e a metafísica, e determinando à ciência natural o estatuto de ser o único conhecimento seguro e verdadeiro. O positivismo, iniciado por Auguste Comte (1798-1857), estabeleceu que o estudo "útil, experimentável e concreto" era somente aquele que pudesse ser "investigado e evidenciado pela ciência" (Bello, 2004, p. 42). O pressuposto comtiano era de que apenas a ciência física conseguia captar, analisar e compreender a realidade; desta forma, a Filosofia não tinha autonomia sobre os objetos de estudo, passando a ser simples reflexão acerca do trabalho propriamente científico (Bello, 2004).

Da mesma forma, as chamadas ciências humanas, antes disciplinas filosóficas, foram se desvinculando da Filosofia no final do século XIX, assumindo o método científico e se constituindo como ciências autônomas. O ser humano, então, passou a ser objeto de estudo cientifico da Psicologia, Antropologia, Sociologia e outros estudos de cunho humanístico-social. Este período foi marcado pela segmentação da realidade por parte da ciência moderna, de forma que "cada aspecto da realidade passa a ser estudado por uma específica área de pesquisa" (Bello, 2004, p. 38).

Historicamente, nas ciências humanas, as pesquisas foram definidas a partir do paradigma positivista, tendo em vista que os pesquisadores buscavam desenvolver uma pesquisa científica experimental, porém, com um método menos rígido e que não exigisse medidas e quantidades com a mesma exatidão das ciências naturais, por problemas de adequação metodológica em relação ao objetivo do estudo (Denzin \& Lincoln, 2006). Ao mesmo tempo, alguns continuadores das ciências humanas, que insistiam nos aspectos culturais e particulares do sujeito humano, foram retomando a problematização do caráter qualitativo e interpretativo das pesquisas científicas naturalísticas. Então, a partir 
das primeiras décadas do século $X X$, as pesquisas chamadas "qualitativas" nas ciências humanas e sociais ganharam novamente relevância. Todavia, as pesquisas qualitativas permaneceram norteadas por aspectos empíricos, com o intuito de assegurar a "cientificidade" do que era investigado.

É nesse contexto de crítica, iniciada nos primórdios do século $X X$, que o filósofo Edmundo Husserl (1859-1938) lança sua crítica ao positivismo, ao naturalismo, à "desumanização" das ciências e denuncia a denominada "crise das ciências". Trata-se de uma crise dos fundamentos das ciências, do abandono da matriz filosófica pela civilização europeia e da negligência quanto à subjetividade do ser humano, ou seja, uma crise epistemológica, existencial e espiritual. Sendo assim, o primeiro impulso de Husserl foi estabelecer uma crítica ao dualismo mentecorpo cartesiano, bem como ao psicologismo naturalista e filosófico, cuja interpretações impossibilitaram uma compreensão da subjetividade humana pura e, consequentemente, desviam o conhecimento do autêntico sentido das ciências (Husserl, 1954/2012).

Frente à crítica ao psicologismo e ao naturalismo que predominava da filosofia, Husserl elaborou a Fenomenologia, que propõe uma compreensão fundamental para a ciência: que os fenômenos sejam evidenciados em essência, para além do empírico (naturalista) e científico (positivista) das hipóteses e teorias. Isto quer dizer restabelecer "a significação para a vida" através da filosofia e compreender os fenômenos da existência humana, com um método rigoroso (Husserl, 1954/2012). Ademais, estabeleceu-a como uma "ciência das essências", diferentemente das "ciências dos fatos", pois tem a intenção de ultrapassar os fatos (positivismo) e os aspectos naturais (naturalismo), com o intuito de chegar "às coisas mesmas", aos significados mesmos constituídos na subjetividade (Goto, 2013).

Enquanto filósofo autêntico, Husserl afirma que "se 'positivismo' quer dizer tanto quanto fundação, absolutamente livre de preconceitos de todas as ciências naquilo que é 'positivo', então somos nós os autênticos positivistas" (Husserl, 1913/2006, p. 64). Desta forma, ele estruturou o método fenomenológico, para dar conta do ser humano de maneira epistemológica e, em 1913, publica a obra "Ideias para uma fenomenologia pura e para uma filosofia fenomenológica", na qual discorre sobre o percurso fenomenológico.

Entrementes à crítica filosófica fenomenológica ao psicologismo e ao positivismo, o psiquiatra suíço Carl Gustav Jung (1875-1961) também na Psiquiatria e Psicologia assentou uma crítica à Psicologia científica e à Psicanálise de S. Freud (1856-1939), elevando as suas ideias à uma teoria psicológica, a qual denominou Psicologia Analítica. Nesta, o psiquiatra e psicoterapeuta apresentou um parecer contrário ao modelo psicológico positivista e naturalista, presente na Psicologia e Psicanálise, evidenciando vários fenômenos que ultrapassam a experiência empírico-psicológica, tais como intuição, sonhos, imaginação e o próprio inconsciente. $\mathrm{O}$ fundamento das experiências ditadas por Jung, bem como seus 
significados, que origina os processos psicológicos conscientes e inconscientes em cada ser humano, foi evidenciado com recursos metodológicos que vão além do dado empírico natural e do pensamento positivista.

Mesmo encontrando em vários escritos a declaração de Jung enquanto cientista empírico (Jung, 1964/2016), ele, ao mesmo tempo, sempre teceu críticas à lógica das teorias científicas, apresentando uma compreensão diferente de empirismo em relação à da ciência convencional, tal como Husserl na Fenomenologia. Em um dos últimos ensaios escritos, publicado na obra "O homem e seus símbolos" (1964/2016), ele ressaltou a vulnerabilidade da busca por fórmulas precisas para explicar os fatos, o que, na verdade, trata-se de um trabalho efêmero, que nunca atinge a verdade absoluta. Fenômenos como o simbolismo, as emoções, os afetos e outros na Psicologia, não podem ser formulados e encerrados em uma definição lógica e absoluta, porque sofrem a intervenção do inconsciente. Além disso, critica que, "à medida que aumenta o conhecimento científico, diminui o grau de humanização do nosso mundo" (Jung, 1964/2016, p. 120).

Estes apontamentos iniciais mostram uma aproximação entre os dois pensadores, principalmente no que diz respeito à crítica ao positivismo, à Psicologia científica e a condução na constituição de outra Psicologia. Ambos pensadores identificam os limites do positivismo, retomaram o projeto histórico-epistemológico do ser humano como base antropológica de uma Psicologia e elaboram uma Psicologia mais humana, que esteja mais em acordo com a sua natureza. Assim, identificouse nesse estudo destacar as convergências críticas da Fenomenologia de Husserl e da Psicologia Analítica de Jung, bem como a correlação de outros possíveis conceitos, estruturações e métodos no que tange a elaboração de uma nova Psicologia.

\section{MÉTODO DO ESTUDO}

Este estudo trata de uma investigação qualitativa bibliográfica, a qual compreende uma revisão téorico-bibliográfica, seguida de reflexão crítica e interpretativa. Conforme Lima e Mioto (2007, p. 38), a "pesquisa bibliográfica implica em um conjunto ordenado de procedimentos de busca por soluções, atento ao objeto de estudo, e que, por isso, não pode ser aleatório" (Lima \& Mioto, 2007). A partir dessa proposta metodológica, este estudo visou um delineamento teórico e epistemológico, explicitando os conceitos e estruturações da Fenomenologia e da Psicologia Analítica, buscando identificar pontos de convergência, nos quais se equiparam e/ou complementam.

Para o seu desenvolvimento estabeleceu-se, como sistematizam Lima e Mioto (2007), quatro etapas principais: identificação do problema, investigação acerca das soluções, análise explicativa das soluções e síntese integradora. Assim, após identificado o problema-questão, passou-se à análise das obras consultadas de C. G. Jung, entre elas: "The Zofingia lectures" (1896/1983), "Os arquétipos e o inconsciente coletivo" (1976/2000), "O homem e seus símbolos" (1964/2016) e 
"Memórias, sonhos, reflexões" (1961/2019); e obras de E. Husserl: "A Filosofia como ciência de rigor" (1910/1965), "Ideias para uma Fenomenologia Pura e uma Filosofia Fenomenológica" (1913/2006) e "A crise das ciências europeias e a Fenomenologia Transcendental - uma introdução à Filosofia Fenomenológica" (1954/2012).

Também foram consultados artigos e livros de pesquisadores que aprofundaram nos estudos junguianos (Camolesi, 1993; Clarke, 1993; Hall \& Nordby, 1980/2014) e estudos husserlianos (Bello, 2004, 2017; Costa, Goto \& Holanda, 2018; Goto, 2007, 2013, 2015; Tourinho, 2011, 2013), o que possibilitou a correlação entre a Fenomenologia e a Psicologia Analítica. Algumas das revistas científicas nacionais consultadas foram: "Aoristo: International Journal of Phenomenology", "Hermeneutics and Metaphysics"; "Encontros com a Filosofia"; "Estudos e Pesquisas em Psicologia"; "Nufen: Phenomenology e Interdisciplinarity"; "Phenomenological Studies: Revista da Abordagem Gestáltica".

No entanto, as contribuições decisivas, que viabilizaram o desenvolvimento da questão, vieram dos estudos do psicólogo estadunidense Roger Brooke, publicado na obra "Pathways into the Jungian world: Phenomenology and analytical psychology" (2005). Também a contribuição secundária dos estudiosos D. Romanyshyn (2005), Schenk (2005) e Mook (2005), que fazem análises de aproximações teórica e metodológica entre Psicologia Analítica e Fenomenologia, trazendo apontamentos que envolvem a intuição enquanto método para alcançar a amplitude dos fenômenos, a atuação do inconsciente e a complexidade da ordem psicológica. Brooke (2005) aponta que o estudo de Jung enfatiza e contribui para a compreensão do ser humano e o significado dos fenômenos psíquicos, tal qual a proposta de Psicologia Fenomenológica de Husserl.

\section{A FENOMENOLOGIA E A CRÍTICA AO POSITIVISMO: A CONSTITUIÇÃO DA PSICOLOGIA FENOMENOLÓGICA}

A Fenomenologia, uma filosofia inaugurada em 1900-1901 com a publicação da obra "Investigações Lógicas", pode ser considerada uma das primeiras grandes críticas ao positivismo, principalmente no quesito epistemológico e metodológico. No entendimento de Husserl, o método científico da época era eficiente e de credibilidade, mas não autêntico para a Filosofia e outras pesquisas de caráter humanístico. Uma das preocupações observadas era que a ciência positivista, de caráter reducionista, desumanizava as vivências e obscurecia o significado das coisas. Em suas últimas obras, afirmou que a ciência positivista decapita a Filosofia e, consequentemente, o ser humano. Desta forma, se dedicou à uma nova perspectiva sobre o mundo, de forma a voltar à consciência das coisas, ao fenômeno em si (Husserl, 1954/2012). 
A compreensão husserliana é de que as ciências positivas, tanto quanto a consciência cotidiana do senso comum, mesmo que de modos diferentes, permanecem no plano empírico-natural, o que expressa sempre uma evidência parcial. Além disso, a lógica positiva descarta tudo que não é exterior, pois apenas o que é palpável e objetivo pode ser estudado; o que não passa de uma "'regra empírica', cuja validade é meramente circunstancial e, portanto, uma regra que carece de exatidão absoluta" (Tourinho, 2011, p. 136). Desta forma, a crítica ao positivismo recai, principalmente, na dissociação entre externo e interno, objetivo e subjetivo, mente e corpo.

Ainda, o estudo científico-empirista fica restrito apenas ao indutivo e probabilístico, o qual consiste em observar fatos objetivos e descrever a regularidade em que acontecem. Então, na acepção de Husserl (1913/2006), não é possível inferir uma lei universal a partir da observação de casos particulares, como propõe o paradigma positivista, apenas chegar às generalizações. No entanto, Husserl contava com o exemplo da matemática e da geometria como possibilidades cognitivas e epistemológicas no conhecimento das coisas, sendo possível então pensar outras maneiras de a racionalidade expressar conhecimentos universais, mantendo a natureza das coisas mesmas. Nesse empenho, Husserl passou a desenvolver um método, cuja atitude fosse reflexiva e analítica, e possibilitasse encontrar o sentido da coisa, "tanto aquele que se atualiza no pensamento quanto às significações que se encontram virtualmente ali presentes" (Tourinho, 2013, p. 11).

Além da crítica epistemológica, Husserl (1954/2012) denuncia a "desumanização" das ciências, apontando para uma "crise das ciências". Trata-se da perda do sentido vital e humano por parte das ciências, pois há um abandono da tarefa racional de buscar as questões fundamentais à existência humana. Ademais, essa crise científica deriva outras crises, por exemplo a cultural, antropológica e psicológica, justamente por desumanizar a verdade e negar o sujeito como agente desta verdade (San Martín, 1987).

Então, diferentemente do paradigma positivista, a Fenomenologia surge para atuar de forma dinâmica, reflexiva e analítica, com o intuito de encontrar o "sentido originário que a coisa expressa, em sua versão reduzida, independentemente da sua posição de existência" (Tourinho, 2013, p. 9). Para isso, ela deve ser entendida como uma ciência do fenômeno, uma analítica intencional, um método e uma ciência de rigor, cujo intuito é voltar às coisas mesmas e superar a crise epistemológica, existencial e espiritual motivada pelos parâmetros positivistas de fazer ciência (Goto, 2013).

Então, na Fenomenologia o "fenômeno" é entendido como tudo o que se mostra à consciência, ou seja:

Todas as coisas que se mostram a nós, tratamos como fenômenos, que conseguimos compreender 0 sentido. Entretanto, o fato de se mostrarem não nos interessa tanto, 
mas, sim, compreender o que são, isto é, o seu sentido. grande problema da filosofia é buscar o sentido das coisas, tanto de ordem física quanto de caráter cultural, religioso etc., que se mostram a nós (Bello, 2017, p. 19).

Desta forma, nas análises fenomenológicas, Husserl evidencia que não é possível separar mundo e consciência, externo e interno, de forma que a Fenomenologia se torna a análise e reflexão de tudo o que se mostra e aparece. Ao mesmo tempo em que tudo o que se mostra, se mostra a alguém, ou seja, se mostra a uma consciência. Por isso, para Husserl, a consciência é sempre consciência de alguma coisa, sendo, por exemplo, a percepção revelada sempre com a coisa percebida, caso contrário não há revelação do perceber; e, sem o perceber, também não há coisa percebida (Goto, 2013).

O termo "consciência" para Husserl "é como um ponto de convergência das operações humanas, que nos permite dizer o que estamos dizendo ou fazer o que fazemos como seres humanos" (Bello, 2017, p. 43). A condição humana é de consciência transcendental, que capta o fenômeno intuitivamente e é capaz de refletir intencionalmente sobre. A intuição, neste caso, possibilita a percepção sensível (empírica) e transcendental (racional) ao mesmo tempo, o que garante que o sentido seja universal. A filósofa e discípula de Husserl, Edith Stein (18911942), reforça que a intuição apreende o que o objeto é tanto em sua singularidade quanto no seu modo de ser das coisas (Goto, 2007).

A Fenomenologia busca, assim, unir os polos científico e psicológico, o que denominou como "a priori da correlação" (Husserl, 1954/2012), descoberta essa que perpassa toda a obra de Husserl e aponta que somente a partir dessa correlação é que se tem a condição humana que possibilita os fenômenos (Goto, 2013).

Se as ciências positivas não deixam de conceber a relação entre subjetivo e objetivo em termos da dicotomia "interioridade" / "exterioridade", assentindo o objetivo como algo que nos remete sempre para um exterior, para o que transcende a própria consciência empírica (ou psicológica), a redução fenomenológica permite-nos, ao nos lançar para o modo transcendental de consideração do mundo, recuperar a autêntica objetividade na própria subjetividade transcendental (trata-se, nos termos de Husserl, de "...uma exterioridade objetiva na pura interioridade"), unindo, com isso, o objetivo e o subjetivo (Tourinho, 2013, p. 10).

Assim, é preciso analisar a consciência e chegar ao ponto universal do fenômeno, que se dá a todo ser humano. Para essa análise, Husserl elaborou e desenvolveu o método fenomenológico, sistematizado inicialmente entre 1904 e 1907 (Goto, 2013). É um método de análise, descrições e confirmações do que é evidente, de forma que qualquer pessoa consiga chegar aos mesmos elementos; esse é o rigor proposto por Husserl. Tem-se no método fenomenológico um trabalho 
"arqueológico de escavação", cuja função é justamente identificar as partes que preenchem o fenômeno, encontrando o sentido universal, a vivência comum, porque quanto maior a riqueza qualitativa da vivência, maior a possibilidade de preencher o fenômeno, de forma a esgotar a análise (Goto, 2013).

O "voltar às coisas mesmas" não significa o retorno às coisas materiais, tal como as ciências positivas, mas sim desenvolver o aspecto transcendental, que é o que integra e sintetiza as partes ao todo, ou seja, as vivências humanas ao fenômeno universal (Goto, 2007). Conforme ressalta Bello (2017, p. 15), "as ciências humanas não podem se constituir efetivamente sem a apreensão adequada do que vem a ser a dimensão espiritual em sua relação com a psique e com a corporeidade".

Neste contexto e à parte dos fundamentos filosóficos da Fenomenologia, Husserl (1954/2012) seguiu como um crítico da Psicologia científica, principalmente ao falar de uma crise epistemológica e da falta de sentido e método. A princípio, a crítica iniciou pela reprovação quanto à questão epistemológica e metodológica em sua constituição, logo se estendeu à ocupação de cadeiras de filósofos por representantes da psicologia experimental. Na ocasião, foi publicado um manifesto de repúdio, o qual obteve 106 assinaturas, incluindo a de Husserl (Araújo, 2013). Comenta Husserl (1913/2006, p. 26) que "de maneira alguma menosprezava o trabalho experimental realizado por homens insignes, mas que punha a nu certas falhas radicais, em sentido literal, do método". Assim, debruçou-se sobre a crítica à Psicologia científica e apontou que apenas o método fenomenológico poderia abranger a área de forma integral, unindo os aspectos subjetivos, tão necessários à compreensão do ser humano.

A rejeição maior estava no fato de a Psicologia científica desprezar a natureza subjetiva do ser humano, estando presa aos aspectos fisiológicos, justamente por tentar se enquadrar no paradigma positivista. A percepção de Husserl era de que a Psicologia, bem como as ciências humanas em geral, havia se tornando insuficiente devido ao fato de ter optado por se referenciar nas ciências empíricas, sem a compreensão de que o objeto de estudo é diferente (Martinelli, 2018). Por isso, a

Psicologia que tem o encargo de estudar a vida psíquica per sie a tarefa de acessar a essência da subjetividade na realidade, de modo científico, natural, não o faz. Ao contrário, acabou desviando-se dessa tarefa pela simples incapacidade do Positivismo em captar o autêntico fundamento da subjetividade (Costa et al., 2018, p. 41).

Este objetivismo é o agente desta crise, pois impede que a Psicologia alcance a "essência da consciência", bem como a subjetividade psicofísica e da natureza humana. Desta forma, Husserl compreendia ser necessário uma nova forma de conceber a Psicologia e somente pelo método da Fenomenologia seria possível uma "autêntica Psicologia", uma "Psicologia Fenomenológica" (Costa et al., 2018). Destarte, o filósofo pôde romper com o psicologismo, corrente filosófica que 
considera a Psicologia como ciência empírica, e mostrar as potencialidades do método fenomenológico para a Psicologia.

A concepção de Psicologia Fenomenológica se apresenta e constitui ao longo de toda a obra de Husserl (Goto, 2015), acompanhando, inclusive, a evolução do método fenomenológico. O filósofo propõe uma nova Psicologia, "que tratará do caráter das essências dos atos intencionais da consciência, ou seja, dos atos psíquicos" (Castañon \& Cormanich, 2018, p. 152). Enquanto a Fenomenologia, propriamente dita, tem o intuito de acessar o essencial à vida psíquica, a Psicologia Fenomenológica visa compreender a essência psíquica a partir do entendimento do fenômeno psíquico humano, ou seja, a "teoria essencial pura do psíquico" (Castañon \& Cormanich, 2018; Goto, 2015).

Afirma Husserl que "não existe uma psicologia pura como ciência positiva [...]. Só existe uma psicologia transcendental, que é idêntica à filosofia transcendental" (Husserl, 1954/2012, p. 208). A Fenomenologia se torna, então, o meio ao qual a Psicologia poderia acessar a subjetividade e "retomar o sentido da humanidade na sua motivação originária" (Costa et al., 2018, p. 45). É necessário que a Psicologia conheça os fenômenos com os quais analisa, estuda, levando em consideração a totalidade do sentido (fenômeno), não apenas o físico e orgânico da Psicologia científica. Para Husserl (1954/2012), a Psicologia Fenomenológica objetiva superar a crise da cientificidade, ao lançar bases para uma Psicologia integral do ser humano (Costa et al., 2018), porque trata-se de uma área do conhecimento, não viabilizando um caminho direto para a intervenção psicológica, mas sim uma reflexão sobre os fenômenos psicológicos; não é uma psicologia empírica, mas transcendental, porque a "pura psicologia não conhece justamente senão o subjetivo, e admitir aí como existente algo de objetivo é já dela ter aberto mão" (Husserl, 1954/2012, p.209).

\section{A PSICOLOGIA ANALÍTICA E SUA CRÍTICA À PSICOLOGIA CIENTÍFICA E À PSICANÁLISE}

A Psicologia Analítica foi fundada aproximadamente em 1917 por Carl Gustav Jung que, conforme Freeman, no prefácio da obra "O homem e seus símbolos" (Jung, 1964/2016), pode ser considerado um dos grandes pensadores do século passado. Um dos marcos da constituição dessa Psicologia é comumente conhecido pelo rompimento com Sigmund Freud (1856-1939), em 1913, a partir do qual começou a elaborar um sistema próprio de Psicologia, estabelecendo ideias, conceitos e métodos que também ultrapassam os limites do pensamento naturalista e cartesiano.

O interesse de Jung (1961/2019) pela Psicologia ocorreu enquanto ainda cursava medicina; ele tinha curiosidade pelos fenômenos "ocultos" que acometiam o ser humano, inclusive em suas experiências pessoais, por isso, em 1899 optou pelo campo da Psiquiatria. No decorrer da especialização, assumiu o cargo de 
assistente do Hospital Psiquiátrico de Burghölzli, local no qual aproveitou para observar empiricamente os pacientes e conhecer a literatura psiquiátrica, época que entrou em contato com a obra de Freud, "A interpretação dos sonhos" (1900) (Jung, 1961/2019).

O primeiro encontro de Jung e Freud aconteceu em 1907 e possibilitou um relacionamento intelectual e profissional durante os seis anos seguintes. No entanto, Jung sempre teve um pensamento e metodologia independentes e pretendia seguir um caminho profissional baseado em suas próprias teorias. E assim o fez quando publicou o livro "Símbolos de Transformação" (1911), abalando a ligação com Freud (Jung, 1961/2019). Uma das principais diferenças entre os pensamentos entre os dois estava sobre a compreensão da psique humana, pois enquanto para Freud tratava de uma interação de duas ou três pulsões sexuais energéticas, para Jung era uma teia complexa de fragmentos da experiência psicológica, tanto consciente quanto inconsciente, que se centraliza na consciência e constitui um sistema que visa sempre o equilíbrio entre os vários fatores (Clarke, 1993).

Também divergiam sobre o inconsciente, Freud acreditava ser apenas um repositório pessoal de experiências reprimidas, em especial as de cunho sexual; enquanto Jung abordava-o de forma ampliada. Afirma Jung (1961/2019, p. 158) que "era evidente que Freud tinha um apego extraordinário à sua teoria sexual".

No entanto, uma das principais críticas de Jung à Psicanálise de Freud, e que ocasionou o rompimento definitivo, foi acerca do termo "libido", que para Freud era exclusivamente de natureza sexual e para Jung se constituía em termos mais amplos, sendo propulsora de energia vital (Clarke, 1993). Por fim, conclui Jung que o método materialista racionalista de Freud, enquanto norte interpretativo da Psicologia, é hostil ao espírito, pois constitui uma Psicologia "sem alma" (Jung, 1931/1991).

Jung (1961/2019) via essa unilateralidade da teoria sexual do Freud, pois vinha de uma formação a partir da leitura de velhos filósofos e tinha conhecimento sobre a história da Psicologia, assim apontava para uma "crise de civilização", a qual é derivada do materialismo racionalista moderno. Essa unilateralidade da razão, predominante a partir do século XIX, mergulhou a civilização em um desequilíbrio, influenciando os processos psíquicos conscientes e inconscientes dos indivíduos. Então, a crítica aponta para o "triunfo da matéria", em que "a matéria é a realidade última e os fenômenos espirituais nada mais são do que uma manifestação desta", o que recai no erro da unilateralidade e da suposta neutralidade (Camolesi, 1993, p. 62).

Jung sabia que somente a prova empírica naturalística e exata não garantia a veracidade das coisas e que não é possível ignorar determinados aspectos imateriais e metafísicos. Na época de estudante de medicina, em uma de suas palestras na Zofingia, afirmou que o "número dos fatos que defendem a existência da alma é legião, sem uma alma esses fatos seriam simplesmente 
impossíveis" (Jung, 1896/1983, p. 19, tradução nossa). Ademais, já apontava uma análise crítica das teorias científicas racionais que levavam, invariavelmente, a algum aspecto do subjetivo, tão negligenciado pela ciência. Apenas o materialismo das ciências exatas não consegue abranger o ser humano e os fenômenos que perpassam a psique, pois existem propriedades transcendentais, inclusive na matéria, que indicam a preexistência de elementos vitais anteriores ao que é orgânico (Jung, 1896/1983).

A posição da opinião materialista contemporânea constitui, simplesmente, uma derrota intelectual. Esta atitude, na verdade, proíbe-nos de ultrapassar limites estreitos. Condena-nos a continuar a recolher dados para depósitos que há muito estão cheios até à borda. Nós melhoramos nossos microscópios, e, a cada dia, tudo que eles fazem é nos revelar novas e maiores complexidades. Nós melhoramos nossos telescópios, e tudo que eles fazem é nos mostrar novos mundos e sistemas. O enigma permanece, e a única mudança é que ele se torna cada vez mais complexo (Jung, 1896/1983, p. 19, tradução nossa).

Sendo assim, Jung iniciou seus estudos pautados nos questionamentos acerca da viabilidade do materialismo para compreender a vida, de forma que, ao dar início à Psicologia Analítica, de fato, ele rompe com a dita "verdade científica" da época, ou seja, com o paradigma positivista - bem como com a Psicologia científica e a Psicanálise freudiana - para analisar os fenômenos que vão além do dado material. Em suas reflexões, Jung aponta que "a única realidade dada de imediato é a experiência psíquica" e que matéria e espírito são domínios complementares da consciência, e é por essa mesma consciência que transcendem e devem estar em equilíbrio (Camolesi, 1993, pp. 63-64). O psiquiatra suíço reconhece a psique de maneira tão relevante quanto o mundo material, porém chegou a dizer:

Todo aquele que deseja conhecer a psique humana não aprenderá quase nada com a psicologia experimental. Seria melhor para ele abandonar a sua beca de especialista, dizer adeus aos seus estudos e errar pelo mundo com o coração humano [...] e [...] por meio do amor e do ódio, e da experiência da paixão sentida em cada forma em seu próprio corpo, ele armazenaria um conteúdo mais rico de conhecimento do que o que poderia ser dado pelos densos textos escolares, e aprenderia a curar os doentes com um conhecimento real da alma humana (Jung, citado por Hoffman, 2005, pp. 171-172).

Mesmo com sérias críticas ao materialismo e positivismo na Psicologia, optou por se manter um empirista, omitindo em vários momentos os pontos de vista filosóficos que lhe incitavam (Clarke, 1993). No entanto, é notório que Jung não mantem o sentido naturalista do empirismo, mas segue um empirismo reformulado segundo suas críticas. A sua ideia de empirismo pode ser identificada quando diz que é: 
[...] um empírico e, como tal, me mantenho fiel ao ponto de vista fenomenológico [...] limito-me, portanto a observar fenômenos e me abstenho de qualquer abordagem metafísica ou filosófica. Não nego a validade de outras abordagens, mas não posso pretender a uma correta aplicação desses critérios (Jung, 1939/1987, p. 7-8).

Não assumindo a ideia de empirismo clássica, tem-se em Jung uma definição de experiência fenomenológica. Não se sabe ao certo se existe uma influência direta da fenomenologia de Husserl, porém há concordâncias em relação à não aceitação do argumento objetivista e naturalista dado pelas ciências.

Todos esses pareceres contribuíram para o desenvolvimento e progresso da Psicologia Analítica, cujo tópicos de maior importância são: personalidade, consciente, inconsciente, arquétipos, símbolos e sonhos. Todos demandam recursos metodológicos distintos e particulares; quase sempre despendendo do uso da intuição, imaginação, do método de desenvolvimento e outros métodos dialético simbólicos que pudessem ser úteis para compreender os problemas que afligiam os pacientes.

A interpretação dos sonhos, por exemplo, não pode acontecer de forma moldada, tendo em vista que é uma tarefa individual e integral. É preciso analisar o particular, pois os sonhos selecionam símbolos universais para um propósito individual, que diz respeito apenas a quem sonha. Isso mostra a forma como Jung rompe com a convenção científica, apesar de sempre ter se comportado como um cientista frente aos objetos de estudo (Hall \& Nordby, 1980/2014).

O que mais interessava Jung era a maneira pela qual os conceitos abstratos, por exemplo os símbolos e sonhos, funcionavam na personalidade e comportamento de um determinado indivíduo. Ele era atraído pela complexidade individual, muito mais do que para teorias científicas, embora reconhecesse a necessidade destas. Conforme destaca Hall e Nordby (1980/2014, p. 102), a "análise (desenvolvimento) tipicamente junguiana é exclusivamente psicológica [...]. A realidade da psique é a única realidade que interessa ao psicólogo; a realidade do mundo exterior é da alçada do cientista físico".

A estrutura da personalidade é o que leva aos outros conceitos estabelecidos na Psicologia Analítica - entre os principais estão psique, consciência, ego, inconsciente pessoal, inconsciente coletivo, arquétipos, individuação e função transcendente. A psique é o todo da personalidade, o que envolve pensamentos, sentimentos e comportamentos, de origem consciente e inconsciente; ela não é fragmentária, mas sim integral, apenas necessita ser desenvolvida para que não se fracione e alcance o todo essencial (Hall \& Nordby, 1980/2014).

A psique é, então, constituída em três níveis: consciente, inconsciente pessoal e inconsciente coletivo. De forma resumida, Jung (1976/2000) determina que a consciência é a parte a qual o indivíduo tem acesso direto; o inconsciente pessoal 
é onde ficam armazenadas as experiências individuais não necessárias ao processo de individuação ou função consciente; e, o inconsciente coletivo trata de um receptáculo de "imagens primordiais", herdadas ao longo da evolução das espécies.

O inconsciente coletivo é a camada mais profunda que possui conteúdos (denominados arquétipos) e sistemas de condutas presentes em todos os indivíduos, independentemente do local; trata-se de uma essência psíquica comum em todos os seres humanos. O arquétipo, apesar de ser um conteúdo essencialmente inconsciente, pode surgir à consciência, de forma que o universal assume características que variam de acordo com o indivíduo no qual se manifesta. Essa manifestação no consciente pode se dar através dos sonhos, dos mitos e, principalmente, dos símbolos. Estes implicam coisas que estão além do que está manifesto ou é imediato, expressões do inconsciente humano apreendidos através de projeção, ou espelhamento, nos fenômenos da natureza (Jung, 1976/2000).

Por fim, a individuação é o processo no qual o indivíduo reúne e conhece todas essas informações da psique, desenvolvendo a autoconsciência. E a função transcendente é o segundo passo para a integração da personalidade, unindo cada parte individuada e atingindo a totalidade (Hall \& Nordby, 1980/2014). Sendo assim, essas duas etapas garantem ao homem o conhecimento e a unidade de todas as partes que integram sua psique.

Enquanto psicoterapeuta e um "cientista empírico" que rompe com a Psicologia científica e a Psicanálise, Jung (1964/2016, pp. 59-60) vai dizer que, para o "equilíbrio mental e mesmo da saúde fisiológica, o consciente e o inconsciente devem estar completamente interligados, a fim de que possam se mover em linhas paralelas. Se se separam um do outro ou se 'dissociam', ocorrem distúrbios psicológicos". Desta forma, a sua "Psicologia com alma" consistia unir as esferas objetivas e subjetivas, essenciais à personalidade do ser humano, assim Jung dá um passo além na Psicologia, buscando profundidade e diferentes técnicas de análise para dar conta da dimensão humana. A Psicologia Analítica "nos oferece novas possibilidades, ao provar a existência de imagens fantásticas que surgem das profundezas obscuras da psique e nos permitiram conhecer os processos que se desenrolam no inconsciente (Jung, 1931/1991, p. 326).

Com a Psicologia Analítica, Jung abordou diversos outros assuntos considerados cientificamente irrelevantes, como a alquimia, astrologia, adivinhação, telepatia, espiritualismo, mediunidade, discos voadores e outros. No entanto, ele não tratava esses assuntos como um seguidor ou adepto, mas sim como psicólogo empírico. A questão fundamental era descobrir como esses temas revelavam sobre a mente, sobre o indivíduo e o inconsciente coletivo. Ele se interessava pela maneira como o universal e abstrato se manifesta em cada indivíduo, mas também advertia que nunca conhecemos a realidade de fato, pois sempre existirão aspectos inconscientes. Quanto mais o homem se individualiza, mais se 
torna capaz de captar os fenômenos e seus significados psíquicos (Hall \& Nordby, 1980/2014). Então, Jung utilizou de todas as fontes disponíveis para alcançar o inconsciente, não se importando o quão estranho, e até mesmo bizarro, pudessem parecer aos cientistas. Jung não se submeteu à convenção científica, mesmo tendo se comportado como cientista ao abordar todos esses assuntos.

\section{APROXIMAÇÕES TEÓRICAS E METODOLÓGICAS ENTRE HUSSERL E JUNG}

Os pioneiros da Fenomenologia foram, geralmente, não simpatizantes com as articulações de Jung. Da mesma maneira, Jung em alguns breves comentários, referindo-se a fenomenologia heideggeriana, não apreciava a associação da Psicologia Analítica à Fenomenologia. Comenta Jung que "o que Heidegger, Klages, Jaspers e outros disseram a esse respeito nunca me afetou profundamente, pois percebe-se logo nos escritores que eles nunca tiveram que lidar com os problemas práticos da psicoterapia" (Jung, 2001, p. 283). Ainda, mais especificamente sobre Heidegger, Jung diz que:

O modus philosophandi de Heidegger é totalmente neurótico e baseia-se em última análise em sua excentricidade psíquica. Os seus afins mais próximos e mais remotos estão em manicômios, alguns como pacientes e outros como psiquiatras com ares filosóficos. Apesar de todas as falhas, o século XIX merece mais do que Heidegger como seu último representante (Jung, 2001, p. 336).

Entretanto, não se tem notícias ou comentários de Jung sobre a Fenomenologia de Husserl. Mesmo assim, é recíproco também a não-simpatia dos principais fenomenólogos pelo pensamento de Jung, como por exemplo H. Spiegelberg (1972) que, em sua obra Phenomenology in Psychology and Psychiatry, tece críticas a autodenominação de Jung enquanto um "fenomenólogo". Para o historiador da fenomenologia, Jung estava utilizando um termo filosófico comum na época, sem aproximações especificas com a escola fenomenológica. No geral, os fenomenólogos criticaram a ontologia e epistemologia implícita de Jung ainda como resquícios cartesiano na tradição do racionalismo e psicologismo do século XIX (Brooke, 2005).

Estudos recentes (Brooke, 2005; D. Romanyshyn, 2005; Mook, 2005; Schenk, 2005) têm mostrado outras posições, correlacionando conceitos abarcados, principalmente entre os pensamentos de Jung e Husserl. Brooke (2005) ressalta que muitas atitudes e posicionamentos de Jung podem ser concernentes à teoria fenomenológica. Por exemplo, a crítica ao reducionismo freudiano, de forma que os fenômenos da experiência devem ser aceitos em seus próprios termos e não reduzidos às vicissitudes da sexualidade edipiana; o método simbólico de interpretação das experiências individuais e coletivas; a abordagem dos 
fenômenos da vida psicológica de forma a não deturpar a integridade da experiência; a ideia do inconsciente, entre outras. Confirma-se isso, a partir desse estudo, pois se verificaram muitas aproximações epistemológicas e metodológicas entre Husserl e Jung, apesar de aparentemente não terem tido uma influência direta.

Ainda, Brooke (2005) aponta que, apesar de Jung se considerar um cientista, sua Psicologia reconstituiu a teoria da personalidade por meio do uso de metáforas (sentidos e significados), recorrendo a fontes pré-iluministas com o intuito de fundamentar a experiência humana. Os métodos de pesquisa junguiano se equiparam ao de Husserl, segundo o autor, no sentido de irem contra a lógica cartesiana, pois são utilizados recursos metodológicos que excedem o dado empírico naturalístico/estatístico, tais como: a intuição, a chegada à essência (ideia/arquétipo) e a relação singular/universal. D. Romanyshyn (2005, p. 37) arrisca até em afirmar que a Psicologia Analítica precisa da Fenomenologia, devido à necessidade de "uma epistemologia radical que vai além do sonho cartesiano da razão".

Conforme visto anteriormente, Jung rompe com o pensamento freudiano por não aceitar a concepção de um inconsciente que é apenas repositório de experiências reprimidas, principalmente de cunho sexual, e o materialismo da Psicologia científica. A crítica de Husserl, por outro lado, trata da cientificidade sendo incorporada na Filosofia e áreas afins, na qual se passou a ter a preponderância dos aspectos físicos e materiais, o que desumaniza o homem. Desta forma, ambos trabalham com a ruptura do pensamento estabelecido na época, bem como uma crítica ao objetivismo da Psicologia científica, a qual impedia uma análise integral do ser humano, da consciência e da estrutura psicológica. Cabe dizer, nesse contexto, que Husserl avançou ao desenvolver o "método fenomenológico", que dissocia do empírico-naturalista da época, enquanto Jung ainda mantinha certo empirismo e cientificismo, pelo menos como nomeava.

A crítica de ambos em relação à Psicologia científica também explicita a dissociação entre objetivo e subjetivo, consciente e inconsciente, material e espiritual. É justamente essa separação que leva à "crise das ciências", para Husserl, e à "crise de civilização", para Jung. A sobreposição da racionalidade, do materialismo e do empirismo moderno sobre os fenômenos psíquicos/espirituais não permite a compreensão integral sobre o ser humano. Desta forma, o pensamento que aproxima as críticas de ambos é que o cientificismo positivista não é adequado e suficiente para conhecer a psique e os fenômenos psicológicos, de forma que ambos formularam um método diferente para captar a essência psíquica do ser humano.

Então, a oposição a esta separação influencia todo o pensamento junguiano e husserliano, incluindo algumas noções importantes para as teorias elaboradas, por exemplo os arquétipos e os fenômenos, respectivamente. De acordo com 
Brooke (2005), a aproximação entre os conceitos está na chegada universalidade; ambos são universais e independentes dos aspectos conscientes experienciais, pois implicam em algo além do que está manifesto ou é imediato. O método fenomenológico de Husserl buscava justamente chegar ao ponto universal do fenômeno, da mesma forma que Jung afirmava que os arquétipos são receptáculos de "imagens primordiais", herdadas ao longo da evolução das espécies, as quais conduzem os indivíduos, independentemente do tempo e local.

Outro ponto importante é o método de análise de Husserl e Jung, o qual rompe com o racionalismo positivista. A intuição, por exemplo, é um dos principais tópicos em ambos os estudos. Entre os fenomenólogos há um compromisso com a intuição do significado como é concretamente dado na experiência, a fim de permitir que os fenômenos se mostrem sem serem obscurecidos pelos pressupostos teóricos, culturais e metafísicos (Brooke, 2005). Jung e Husserl possuíam uma a base filosófica kantiana/bergsoniana para conceituar a "intuição", porém foram adiante, evidenciando que o ser humano captura além dos dados sensíveis. Há uma captação imediata, sem razão, da sensibilidade e do sentido (significado). Parece que Jung fica mais restrito em uma posição kantiana/bergsoniana, enquanto Husserl realmente procede um passo adiante, ao sugerir que a sensibilidade e o sentido acontecem simultaneamente, ou seja, a intuição é sensível e dos sentidos (Goto, 2013).

De qualquer forma, o uso da intuição desloca Jung e Husserl da ciência convencional; independente dos conceitos e métodos, os dois tentaram recuperar e compreender o explícito e o implícito das experiências vividas, indo além do que o pensamento matemático da época estabelecia como científico.

A Fenomenologia é considerada uma analítica intencional, pois a condição humana é de consciência transcendental, que capta o fenômeno intuitivamente, antes mesmo da reflexão (Goto, 2007). Segundo Husserl (1913/2006) é a partir da intuição que se tem a "autopresentificação originária" (originale Selbstdarstellung), porque, em qualquer intuição, o que é dado (das Gegebene) é dado "em pessoa", ou seja, por ele mesmo (es Selbst) em "carne e osso" e em suas várias maneiras de dação. Jung também analisa o fenômeno, como mostra Brooke (2005), pela manifestação dos arquétipos que são captados intuitivamente, e somente assim, pode-se refletir sobre eles. Jung procede, assim, uma análise do universal nos fenômenos psicológicos, de forma a compreender o universal no particular em cada paciente (Brooke, 2005).

Schenk (2005), por exemplo, aponta para a análise dos símbolos, na qual os psicoterapeutas junguianos são sensíveis às dimensões "simbólicas" da experiência das coisas e às maneiras com que estas se "presenciam" enquanto materialidade dentro da vida psicológica. E, Mook (2005), conclui que os estudos referentes à natureza do inconsciente coletivo, envolvendo os arquétipos, os padrões de desenvolvimento psicológico, o processo de individuação e outros 
tópicos, levaram a uma importante teoria da pessoa, que pode aprofundar uma compreensão fenomenológica; sendo assim, "os principais conceitos junguianos podem ser submetidos a um rigoroso processo fenomenológico e análise hermenêutica".

Por fim, a Fenomenologia e a Psicologia Analítica são responsáveis por importantes contribuições à compreensão da natureza e das complexidades do ser humano no mundo. Os conceitos de ambas podem ser vistos como "contra movimentos para o ponto de vista científico natural e generalizado da psicologia convencional, nos quais os sujeitos humanos são objetivados e distanciados de seus próprios corpos, dos outros e das coisas ao seu redor" (Mook, 2005, p. 233). Com as propostas da Psicologia Fenomenológica e da Psicologia Analítica são viabilizados novos métodos para uma Psicologia que consiga, de fato, abranger o homem em sua totalidade, nos aspectos universais que captam os sentidos objetivos e subjetivos.

\section{CONSIDERAÇÕES FINAIS}

A partir do aprofundamento teórico discorrido, este estudo visou estabelecer, brevemente, possíveis pontos de convergência, entre o pensamento de Husserl e Jung, principalmente no que concerne à crítica ao positivismo e à Psicologia científica. É possível, então, fazer aproximações entre a proposta fenomenológica e a Psicologia Analítica.

A princípio, considera-se a universalidade e totalidade como aspectos inerentes ao pensamento husserliano e junguiano. Husserl pontuava que o ser humano capta o fenômeno todo, apesar disso é preciso que o homem vá captando as partes, desenvolvendo sua capacidade de ver o todo do fenômeno. De maneira semelhante, Jung fundamentava que a personalidade é um todo, e não reunião de partes, como muitas teorias psicológicas afirmavam, no entanto cabe ao homem desenvolver toda sua personalidade e cuidar para que não se fracione.

Outro ponto é que a meta da Fenomenologia é conhecer o fenômeno tão completamente quanto possível, bem como a meta da individuação junguiana é conhecer a si mesmo integralmente. O processo de individuação é semelhante ao processo de escavação do fenômeno; apesar de serem autônomos e inatos, precisam de experiências adequadas e da consciência para que sejam apreendidos em sua totalidade pelo homem. Neste processo, é possível que vá se tornando consciente o que está na inconsciência, ou, na terminologia husserliana, adentre $o$ aspecto transcendental. Inclusive, o termo transcendente se assemelha, no sentido que ambas visam a totalidade; para Husserl, do fenômeno, para Jung, da personalidade.

Tanto Husserl quanto Jung elaboraram uma nova concepção filosófica para a Psicologia, reagindo ao paradigma materialista e naturalista do positivismo. Ambos ampliaram o conceito de experiência (empiria); desenvolveram um 
método que levasse em consideração objetivo e subjetivo, corpo e mente, externo e interno; e, por fim, fundaram uma Psicologia mais humana.

Também neste espaço, suscita-se outros questionamentos, para investigações posteriores. Para Husserl, os três níveis para a compreensão do fenômeno envolvem o físico, a consciência e o espírito, e em Jung, os três níveis na psique são a consciência, o inconsciente pessoal e o inconsciente coletivo; é possível correlacionar estes termos em nível hermenêutico e/ou epistemológico? Outra questão: o que seria necessário para que o desenvolvimento dos conceitos psicológicos propostos por Jung fosse enquadrado em uma análise fenomenológica e, até mesmo, de uma Psicologia Fenomenológica?

Finalizando, ainda hoje é necessário refletir sobre a seguinte afirmação de Bello (2017): "não se faz ciência humana sem que saiba o que é o ser humano. Frequentemente falta o fundamento, infelizmente, está é uma tendência de nosso tempo". Arrisca-se dizer que Jung, tal como Husserl, buscou esse fundamento para os fenômenos individuais e sociais, por uma visão ampla, abarcando todos os sentidos necessários à apreensão do que é ser humano.

\section{REFERÊNCIAS}

Araújo, S. F. (2013). O manifesto dos filósofos alemães contra a psicologia experimental: introdução, tradução e comentários. Estudos e Pesquisas em Psicologia, 13(1), 298-311. Rio de Janeiro. Recuperado em 20 de janeiro de 2020, de http://pepsic.bvsalud.org/pdf/epp/v13n1/v13n1a18.pdf.

Bello, A. A. (2004). Fenomenologia e ciências humanas. Psicologia, história e religião. Bauru, SP: Edusc.

Bello, A. A. (2017). Introdução à Fenomenologia. Belo Horizonte, BH: Spes Editora.

Brooke, R. (2005). Pathways into the Jungian world: Phenomenology and analytical psychology. Londres: Routledge.

Camolesi, M. E. D. (1993). A unilateralidade da razão. A crítica junguiana (Dissertação de mestrado). Fundação Getúlio Vargas, Rio de Janeiro.

Castañon, G. A., \& Cormanich, E. L. (2018). O conceito de psicologia fenomenológica na obra husserliana e suas implicações para a psicologia. Revista Nufen: Phenomenology and Interdisciplinarity 103), 143-165. doi:10.26823/RevistadoNUFEN.vol10.n03artigo41

Clarke, J. J. (1993). Em busca de Jung. Indagações históricas e filosóficas. Rio de Janeiro, RJ: Ediouro.

Costa, I. I. D., Goto, T. A., \& Holanda, A. F. (2018). Fenomenologia transcendental e a psicologia fenomenológica de Edmund Husserl. Revista Nufen: Phenomenology and Interdisciplinarity 103), 38-53. doi:10.26823/RevistadoNUFEN.vol10.n03artigo35

Denzin, N. K., \& Lincoln, Y. S. (2006). Introdução: A disciplina e a prática da pesquisa qualitativa. In N. K. Denzin, \& Y. S. Lincoln (Eds.), O planejamento da pesquisa qualitativa: Teorias e abordagens. (2a ed). Porto Alegre, RS: Artmed.

D. Romanyshyn, R. (2005). Alchemy and the subtle body of metaphor: Soul and cosmos. In R. Brooke (Ed.), Pathways into the Jungian world: Phenomenology and analytical psychology. Londres: Routledge.

Goto, T. A. (2007). A (Re)constituição da Psicologia Fenomenológica em Edmund Husserl. São Paulo, SP: PUC Campinas.

Goto, T. A. (2013). Introdução à fenomenologia de Edmund Husserl e à psicologia fenomenológica. Belo Horizonte (MG): Fundação de Saúde Integral Humanística. [Arquivo de vídeo]. Recuperado em 04 de outubro de 2019, de: https://www.youtube.com/watch?v=_RR9dHtF3e4.

Goto, T. A. (2015). Introdução à psicologia fenomenológica: A nova psicologia de Edmund Husserl. São Paulo, SP: Paulus. 
Hall, C., \& Nordby, V. (2014). Introdução à psicologia junguiana. São Paulo, SP: Cultrix. (Trabalho original publicado em 1980).

Henry, J. (1998). A revolução científica e a historiografia da ciência. In Revolução científica e as origens da ciência moderna. Rio de Janeiro, RJ: Jorge Zahar Ed.

Hoffman, E. (Ed.). (2005). A sabedoria de Carl Jung. São Paulo, SP: Palas Athenas.

Husserl, E. (1965). A Filosofia como ciência de rigor. Coimbra: Atlantida. (Trabalho original publicado em 1910).

Husserl, E. (2006). Ideias para uma fenomenologia pura e uma filosofia fenomenológica. Aparecida: Ideias e Letras. (Trabalho original publicado em 1913).

Husserl, E. (2012). A crise das ciências europeias e a fenomenologia transcendental. Uma introdução à filosofia fenomenológica. Rio de Janeiro, RJ: Editora Forense Universitária. (Trabalho original publicado em 1954).

Jung, C. G. (1983). The Zofingia lectures. In The Collected Works Suplementary. Londres: Routledge $\&$ Kegan Paul. (Trabalho original publicado em 1896).

Jung, C. G. (1987) Psicologia e religião. Petrópolis, RJ: Vozes (Trabalho original publicado em 1939).

Jung, C. G. (1991). Psicologia analítica e cosmovisão. In Natureza da Psique. Petrópolis, RJ: Vozes: Vozes. (Trabalho original publicado em 1931).

Jung, C. G. (2000). Os arquétipos e o inconsciente coletivo. (6a ed.) Petrópolis, RJ: Vozes. (Trabalho original publicado em 1976).

Jung, C. G. (2001). Cartas de C. G. Jung: 1906-1945. (vol. I). Petrópolis, RJ: Vozes.

Jung, C. G. (2016). O homem e seus símbolos (3a ed.). Rio de Janeiro, RJ: Harper Collins. (Trabalho original publicado em 1964).

Jung, C. G. (2019). Memórias, sonhos, reflexões. Rio de Janeiro, RJ: Nova Fronteira. (Trabalho original publicado em 1961).

Lima, T. C. S. \& Mioto, R. C. T. (2007). Procedimentos metodológicos na construção do conhecimento científico: A pesquisa bibliográfica. Revista Katálysis, 10(spe), 37-45. doi:10.1590/S1414-49802007000300004

Martinelli, A. V. (2018). As origens do pensamento de Edmund Husserl: Do psicologismo à fenomenologia. Revista Peri, 101), 36-57.

Mook, B. (2005). Phenomenology, analytical psychology, and play therapy. In R. Brooke (Ed.), Pathways into the Jungian world: Phenomenology and analytical psychology. Londres: Routledge.

San Martín, J. (1987). La fenomenología de Husserl como utopía de la razón. Barcelona: Anthropos.

Schenk, R. (2005). Spirit in the tube: The life of television. In R. Brooke (Ed.), Pathways into the Jungian world: Phenomenology and analytical psychology. Londres: Routledge.

Spiegelberg, H. (1972). Phenomenology in Psychology and Psychiatry. Evanston: Northwestern University Press.

Tourinho, C. D. C. (2011). A crítica da Fenomenologia de Husserl à visão positivista nas ciências humanas. Revista da Abordagem Gestáltica, 17(2), 131-136.

Tourinho, C. D. C. (2013). A crítica de Husserl ao positivismo. Revista Virtual EnFit. Encontros com a Filosofia, 1, 1-12.

\section{CONFLITOS DE INTERESSES}

Não há conflitos de interesses.

\section{SOBRE OS AUTORES}

Carolina Rodrigues de Oliveira é graduada em Comunicação Social, habilitação em Jornalismo pela Universidade Federal de Uberlândia (UFU); mestranda em Psicologia pela UFU.

E-mail: carolina r.oliveira@hotmail.com

\section{(1) https://orcid.org/0000-0002-1419-1691}

Tommy Akira Goto é professor da Pós-graduação de Psicologia e da Pós-graduação em Filosofia da Universidade Federal de Uberlândia - UFU, Doutor em Psicologia Clínica (PUC-Campinas), Mestre em Ciências da Religião (Universidade Metodista de São Paulo), Membro do Grupo de Trabalho Fenomenologia na Associação Nacional de Pós Graduação em Filosofia (ANPOF), Membro- 
colaborador do Circulo Latinoamericano de Fenomenologia (CLAFEN), Membro-assistente da Sociedad Iberoamericana de Estudios Heideggerianos (SIEH).

E-mail: tommy@ufu.br

(1) http://orcid.org/0000-0003-4972-7801 